\title{
DESARROLLO DE LAS COMPETENCIAS SOCIOCULTURAL Y PRAGMÁTICA EN ESPAÑOL A TRAVÉS DE PROGRAMAS TELEVISIVOS
}

\author{
SARA DEL VALLE REVUELTA ${ }^{1}$ \\ Universidad de Valladolid
}

\section{Resumen}

Este artículo explica algunos de los motivos por los que el programa televisivo puede resultar útil como recurso para trabajar las competencias pragmática y sociocultural en la clase de español para extranjeros, con el objetivo de aportar nuevas ideas a todos aquellos profesores interesados en el uso del material audiovisual en el aula de español.

Palabras clave: Competencia pragmática, competencia sociocultural, recurso didáctico, material audiovisual, programa televisivo

\begin{abstract}
This article presents some of the reasons that television programs are useful teaching resources for developing sociocultural and pragmatic competences with Spanish-as-a-second-language students. The objective of this study is to present new ideas to teachers interested in using audiovisual content in the Spanish classroom.
\end{abstract}

Key words: Pragmatic competence, social competence, teaching resource, audiovisual content, television program

\section{INTRODUCCIÓN}

Este artículo trata sobreel desarrollo de la competencia sociocultural y pragmática en español a través de programas televisivos ${ }^{2}$. Creemos que estos programas ofrecen la posibilidad de trabajar algunos de los componentes de la competencia comunicativa: el componente lingüístico, el sociolingüístico y el pragmático. No obstante, en este artículo nos centraremos en la explotación de los dos últimos, ya que consideramos que una de las principales ventajas de trabajar con los programas televisivos es su gran contenido cultural. Este es destacable porque se trata de formatos elaborados en el país para cuya población están destinados. En cuanto a aquellos basados en formatos

\footnotetext{
${ }^{1}$ Universidad de Valladolid. Correo: dvrsara@gmail.com. Recibido: 05-05-2015. Aceptado: 15-09-2015.

${ }^{2}$ Basado en la memoria de investigación Desarrollo de las competencias sociocultural y pragmática en español a través de programas televisivos: Una aplicación didáctica para estudiantes francófonos (2014) defendida en la Universidad de Alcalá por la autora de este artículo, Sara del Valle Revuelta, y dirigida por la doctora en Filología Hispánica, Marta Albelda Marco.
} 
globalizados, aun presentando características generales, siempre están adaptados al país donde son retransmitidos: localizaciones de rodaje, concursantes, presentadores, equipo de realización, lenguaje, etc.

A diferencia del largometraje, el cortometraje y otro tipo de formatos audiovisuales, el uso del programa de televisión en la clase de español como lengua extranjera no parece tan habitual, quizás por no ser considerado un material educativo. Además, al no ser comercial, está fuera de las redes tradicionales de distribución. Sin embargo, es lo más cercano a la realidad que el docente puede introducir en su aula. Es una forma indirecta de conocer el entorno sociocultural (gestos, registros, situaciones...). Se caracteriza por ser en directo, lo que origina una forma de lenguaje más natural que la del relato fílmico.

Es un material auténtico que va dirigido a los nativos, de ahí que los estudiantes lo tomen como algo mucho más motivador quecualquier ejercicio o documento manipulado y adaptado para ellos; al comprender este tipo de material, aumenta su autoestima y se sienten con la capacidad de desenvolverse en el país de la lengua estudiada.

Puesto que una de las tareas del profesor de una lengua extranjera consiste en exponer a los alumnos a muestras de lengua auténtica y dado que el uso de los documentos audiovisuales es una necesidad y una práctica de consumo actual, este artículo tiene el objetivo de exponer algunos de los motivos por los que se debería dar cabida en las clases de español a este género audiovisual.

\section{LA COMPETENCIA AUDIOVISUAL Y SUS IMPLICACIONES EN LA EN- SEÑANZA}

Los materiales auténticos pueden ser muy variados: periódicos, revistas, folletos publicitarios, catálogos, prospectos, grabaciones de la radio o de la televisión, etc. “Lo más importante es que este tipo de materiales muestran ejemplos de lengua usada de manera natural, no en el sentido de realista, sino de verdadera" (Ruiz Fajardo, 1994: 143).

De entre todos ellos, nos gustaría destacar el papel del material audiovisual. El vídeo nos permite presentar situaciones comunicativas en contexto y mostrar aspectos culturales. Además, posibilita la presencia e integración de las cuatro destrezas lingüísticas en una misma actividad. Igualmente, cabe destacar que, gracias a Internet, se ha hecho mucho más fácil conseguir este tipo de material, pues este medio permite el acceso directo a todo tipo de documentos auténticos de diferente carácter y nivel de dificultad.

Según Lonergan (1985: 18-21), "la característica principal de los vídeos es su capacidad para presentar situaciones comunicativas completas". De acuerdo con este autor, la combinación de sonido e imagen resulta dinámica, inmediata y accesible, lo que significa que muestra la comunicación en contexto y que los espectadores -en este caso alumnos de lenguas- perciben con facilidad los diversos componentes que entran en juego en la comunicación. Los alumnos ven y oyen a los interlocutores de un diálogo y demás participantes en la situación; advierten la edad de los personajes, su 
sexo, el tipo de relación entre ellos, condición social, actividad... e incluso su estado de ánimo o sus sentimientos.

Además, disponen de información paralingüística, como las expresiones del rostro o los gestos de las manos, que acompañan a los indicadores orales de la entonación, así como de información lingüística. Es un hecho que aquellos alumnos que alguna vez han estado "enganchados" a telenovelas, series, dibujos animados, etc. suelen presentar un mayor nivel de la lengua en cuestión.

\section{EL RECURSO DEL PROGRAMA DE TELEVISIÓN PARA TRABAJAR EL ENFOQUE COMUNICATIVO}

El MCER (Marco Común Europeo de Referencia) propone un enfoque comunicativo centrado en la acción, es decir, un aprendizaje y uso de la lengua en un contexto social amplio y en el que se realizan tareas que activan competencias comunicativas y que requieren el uso de estrategias. Con este objetivo, durante el proceso de aprendizaje se utilizan documentos auténticos y se realizan actividades que intentan imitar fielmente la realidad fuera del aula.

Podríamos pensar que este tipo de material no involucra al receptor en el acto comunicativo que muestra. Sin embargo, el vídeo nos permite utilizar dos tipos de textos que sí involucran al aprendiz. En primer lugar, los textos televisivos, que exigen del estudiante una actitud pasiva, una respuesta desde el entusiasmo al aburrimiento, pasando por toda la gama de reacciones y sentimientos que son los mismos que pueden provocar en los hablantes nativos, pues están pensados para eso. En segundo lugar, las vídeograbaciones, donde el estudiante se observa a sí mismo tomando parte en una interacción en la lengua objeto (Ruiz Fajardo, 1994: 144).

Una manera de trabajar el enfoque comunicativo por medio de un programa de televisión puede consistir en elaborar en grupo programas (role play) a partir de otros programas auténticos grabados de la televisión en la lengua objeto. Es decir, a partir de modelos que proporcionen el caudal de lengua (input) necesario. Cada grupo decide, de acuerdo con las preferencias de sus miembros, el número de actores, sus roles, si algunos estudiantes se quedan tras la cámara, etc. Así, se fomenta el trabajo en equipo, lo que favorece la adquisición de la competencia comunicativa.

Además, la grabación proporciona al profesor y a los alumnos un acceso directo a los errores y permite a los estudiantes enfrentarse a ellos y reconocerlos personalmente. Esta autoevaluación por parte de los propios alumnos puede ayudarles mucho, sobre todo, al darles la oportunidad de observarse a sí mismos hablando español (Ruiz Fajardo, 1994: 158). 


\section{VENTAJAS DE LA INTEGRACIÓN DEL PROGRAMA DE TELEVISIÓN EN LA ENSEÑANZA ELE}

Como hemos mencionado anteriormente, una de las principales ventajas es la motivación. Ferrés Prats (1994: 127) sostiene que la mayoría de las imágenes televisivas pueden servir como programa motivador. Bastará con que tengan capacidad de seducción y el profesor las sepa integrar en una unidad didáctica. Además, como hemos señalado, el alumno tiene la posibilidad de seguir mejorando su capacidad de comprensión audiovisual de manera autónoma con un producto fácilmente adquirible.

Otra ventaja del programa de televisión es que estimula el interés del alumno por adquirir nuevos contenidos de todo tipo. Al ser un material auténtico, incluye contenidos sociales, culturales, políticos, pragmáticos, etc. del país originario de la lengua que se estudia, lo que nos permite conocer esta cultura de una forma amena y dinámica.

Asimismo, al transmitir ejemplos de comunicación auténtica y espontánea, les presenta muestras reales de lengua. La íntima relación de los programas televisivos con el contexto social y cultural conlleva que normalmente el lenguaje utilizado sea muy coloquial y expresivo, reflejo de lo que el alumno se va a encontrar en la calle. También ofrece al espectador diversos registros lingüísticos, una amplia tipología textual y pone en contacto al estudiante con diferentes variantes lingüísticas del español. Del mismo modo, ofrece la posibilidad de tratar en la clase de ELE cuestiones como los estereotipos, los clichés uniformados, las costumbres idealizadas, los modelos contraculturales, etc.

Los gustos y las preferencias de los espectadores se han ido polarizando en una doble dirección, dependiendo del contenido de la información que desean recibir. Según esta bipolarización, el espectador acude al cine cuando busca la evasión, cuando atrae la ficción, el ensueño y la fantasía, cuando siente la necesidad de identificarse con los héroes y -por el contrario- contempla la TV cuando desea acercarse a la realidad conocer el suceso inmediato, la noticia. El espectador identifica realidad con TV e imaginación con cine (Soler, 1988: 120).

Soler (1988: 120) explica una de las claves diferenciales de la televisión frente a su más inmediato competidor: el cine. Los géneros, espacios y modos de trabajo más propiamente televisivos se caracterizan por ser en directo, lo que origina una forma de lenguaje que, de entrada, rehúye la narrativa sincopada propia del relato fílmico, ya que carece de un guión estricto. El programa televisivo refleja no solo los momentos interesantes de la acción, sino también los tiempos muertos, las transiciones, las interrupciones, etc. Además, posee el interés adicional de presentar los hechos en el mismo momento en que se están produciendo, lo que exculpa a su lenguaje de ciertas limitaciones y hasta de cierta pobreza y monotonía.

Otra ventaja es su corta duración, que nos permite trabajar con agilidad y rapidez, variando las actividades y practicando varias destrezas. La mayoría tienen pocos diálogos, lo que nos permite realizar actividades sencillas de audición. Igualmente, no implica el esfuerzo de atención y comprensión, por parte de los alumnos, que exigen otro tipo de materiales audiovisuales como los documentales o las películas. Estos últimos, además, no muestran actos comunicativos espontáneos, sino que están a caballo entre la lengua hablada y la escrita, ya que proceden de guiones (Ruiz Fajardo, 1994: 152). 


\section{CRITERIOS DE SELECCIÓN DE PROGRAMAS DE TELEVISIÓN PARA LA ENSEÑANZA DE E/LE}

La cantidad de material disponible puede ser uno de los grandes problemas a la hora de elegir adecuadamente: ¿qué tipo de documentos seleccionar?, ¿qué características deben tener para ser "documentos auténticos"?, ¿qué variedad del español han de mostrar?, ¿qué cultura hispánica tienen que representar?... Además, el profesor se encuentra con la cuestión de cómo explotarlos didácticamente (Ferrer Plaza, 2009: 2363).

Para aprovechar este potencial motivador, los textos con que se va a trabajar deben despertar el interés del alumno. Del mismo modo que en la vida real solo escuchamos lo que nos interesa, nuestros alumnos solo se implicarán en comprender el mensaje si sienten alguna curiosidad por la información que van a recibir (Soriano Fernández, 2009: 38-39). Por ello, el punto de partida ideal a la hora de seleccionar un programa de televisión y diseñar con él una unidad didáctica sería el realizar encuestas a nuestros alumnos para conocer sus gustos, pues de esta manera tendríamos ganado su interés desde el principio. Por supuesto, el profesor valorará el potencial didáctico del programa televisivo elegido, y decidirá la apropiada secuencia de trabajo, la tipología de actividades que se va a aplicar, así como la adecuación de la actividad a la situación docente.

Al contrario de lo que podríamos pensar, no es imprescindible que los programas televisivos sean didácticos. Como afirma Ferrés Prats (1994: 128), cualquier imagen puede serlo si se sabe integrar en una unidad didáctica. Tanto en las noticias como en los anuncios y en los programas de variedades, hay ejemplos de neologismos, de variaciones dialectales, de utilización de un lenguaje de argot, de incorrecciones o deficiencias expresivas, de variación en los registros expresivos...

Por otra parte y de acuerdo con Ferrer Plaza (2009: 2366-2367), los profesores debemos tener muy en cuenta que los documentos auténticos pueden presentar estructuras, vocabulario o contenidos culturales aún desconocidos para el alumno. Esto puede provocar que la pretendida motivación que tendría que despertar en ellos el documento se convierta en desmotivación al verse incapaces de comprender lo que se les presenta. Para evitar que esto ocurra, el profesor deberá tener en cuenta lo siguiente:

- El documento auténtico debe ser seleccionado de acuerdo con el nivel de lengua de los alumnos.

- Se realizará una serie de actividades previas que tendrán como objetivo practicar y resolver las posibles dificultades que el profesor presupone que los alumnos tendrán a la hora de usar el documento. Estas dudas pueden ser gramaticales, de vocabulario, socioculturales...

- Las actividades estarán siempre centradas en el documento que estemos usando en ese momento en la clase y las tareas estarán relacionadas con las destrezas comunicativas que utilizaría un nativo al usar ese documento. 
- Se privilegiarán los enfoques comunicativos a la hora de explotar didácticamente el documento. Quizá el más apropiado sea el enfoque por tareas por poseer varias características adecuadas para potenciar los aspectos más interesantes del documento auténtico: la implicación de los estudiantes, la similitud de las tareas con las realizadas por los hablantes nativos, la práctica global de las cuatro destrezas, el favorecimiento de aspectos lúdicos $\mathrm{y}$ afectivos en las actividades, el uso del documento con objetivos claros y concretos...

- Por otra parte, del mismo modo que no existe un enfoque "ideal" para la enseñanza de lenguas, tampoco lo hay a la hora de explotar estos documentos. Será la elección personal del profesor (o en ocasiones con la cooperación de los alumnos) en función de las características del grupo, el nivel, los objetivos, el contexto académico, el documento utilizado... la que finalmente determine qué método o métodos usará para cumplir los objetivos planteados.

\section{6. ¿QUÉ ASPECTOS SOCIOCULTURALES Y PRAGMÁTICOS TRABAJAR CON PROGRAMAS DE TELEVISIÓN?}

\subsection{Contenidos socioculturales}

$\mathrm{Si}$, desde una perspectiva comunicativa, queremos que el estudiante sea competente, es decir, que no tenga solo conocimientos sobre la sociedad, sino que estos conocimientos le sirvan para actuar en ella o con los individuos que hacen uso de la lengua-meta, es necesario abordar la competencia cultural.

Las competencias sociolingüísticas se refieren a las condiciones socioculturales del uso de la lengua. Incluyen las normas de cortesía, las normas que ordenan las relaciones entre generaciones, sexos, clases y grupos sociales y la codificación lingüística (MCER, 2002: 2.1.2.).

Algunos pensarán que esto no es demasiado importante, que los alumnos lo aprenderán cuando vayan al país y lo vean, o que el sentido común les ayudará a desenvolverse en las diferentes situaciones. Puede que tengan razón, pero creemos que es mejor no dejar todos estos aspectos al azar y trabajarlos con anticipación en el aula.

Miquel y Sans (1992: 15-21) explican que el concepto de cultura abarca todo lo pautado, lo no dicho, aquello que todos los individuos, adscritos a una lengua y cultura, comparten y dan por sobreentendido.

Podemos concluir que enseñando la lengua, entendida como un instrumento de comunicación, se enseñan, aun sin ser consciente de ello, una serie de prácticas sociales y de valores culturales. Difícilmente se llegará a potenciar en el estudiante la competencia comunicativa en una lengua extranjera, si no se considera la competencia cultural como uno de sus componentes básicos de la enseñanza. 
No estamos diciendo con esto que el extranjero que aprende una lengua deba pretender comportarse en todo momento como un miembro de la comunidad que habla esa lengua, sino que tiene derecho a tener un máximo de información para, de una forma consciente, elegir en todo momento entre transgredir o respetar las pautas culturales esperadas (Miquel y Sans, 1992: 15-21).

Para conseguir transmitir todos estos contenidos socioculturales a sus alumnos, es importante que el profesor de ELE sea capaz de "hacerlos visibles". Creemos que el programa de televisión es una buena herramienta para lograr este fin. El alumno valorará el uso en clase de materiales que forman parte de la vida cotidiana de los hablantes nativos; este aspecto acercará su aprendizaje a una realidad que él siente más cercana al uso auténtico del lenguaje que harían en un país hispano. El profesor puede realizar un trabajo de comparación y contraste sociocultural a través de los programas televisivos, por ejemplo, comparar la versión del país de origen de los estudiantes con la versión española del mismo formato, pues cada una de ellas estará adaptada al público del país donde se retransmiten.

\subsection{Pragmática}

Las competencias pragmáticas se centran en el uso de los recursos lingüísticos (producción de funciones del lenguaje y de actos de habla) sobre la base de guiones o escenarios de intercambios comunicativos. También están relacionadas con el dominio del discurso, la cohesión y la coherencia, la identificación de tipos y formas de texto, la ironía y la parodia (MCER, 2002: 2.1.2.).

Cuando comunicamos, para seleccionar la lengua que producimos, debemos tener en cuenta el contexto y los interlocutores. Aquí aparece uno de los elementos fundamentales de la pragmática: la intención. Esta debe ser entendida por el oyente para conseguir el éxito comunicativo y evitar los malentendidos. Junto con ella, otro elemento fundamental que hay que tener en cuenta es el de la distancia social entre los interlocutores.

Escandell (2004: 45-57) afirma que "enseñar una lengua lleva asociado, por tanto, enseñar a percibir y a evaluar las situaciones y las relaciones sociales tal y como las perciben y las evalúan los nativos, para poder adaptar el comportamiento lingüístico propio a los mismos parámetros que ellos".

A través de los programas televisivos, podemos ofrecer a nuestros estudiantes de ELE muestras de las diferentes modalidades discursivas orales: podemos trabajar tanto el registro coloquial como el formal mediante el visionado y análisis de debates, entrevistas, reportajes, anuncios, reality shows, etc.

Dentro del grupo de géneros del discurso oral están las conversaciones, cara a cara o telefónicas, y también las que se han desarrollado a partir de la cibertecnología, como el chat, los foros de opinión o los blogs (Albelda y Fernández, 2006: 3).

La conversación cara a cara constituye lo que se ha denominado la situación canónica de la comunicación. Es la forma más directa, natural y espontánea del lenguaje. 
Muchas de las categorías lingüísticas (temporalidad, modalidad, referencia, deixis...) están ligadas a esta situación comunicativa. Al margen de sus valores lingüísticos, conversar es una actividad regida por principios comunicativos que trascienden las puras reglas gramaticales. Se trata también de normas de buena conducta comunicativa que el usuario de la lengua nativa va adquiriendo (Gutiérrez Ordóñez, 2004: 33).

En la mayoría de programas televisivos, la conversación espontánea está muy presente, por lo que la utilización de este tipo de material en el aula de ELE puede facilitar la tarea del profesor de familiarizar al estudiante con el valor que en nuestra cultura asumen determinados actos de habla en la conversación coloquial: insultos empleados como vocativos, que no insultan; actos directivos sin atenuar, que no ofenden; halagos y cumplidos aceptados; consejos ofrecidos sin previa petición; insistencia en los actos de ofrecimiento; situaciones que requieren cortesía y formas de expresarla, situaciones que resultan conflictivas o pueden amenazar la imagen de los interlocutores $\mathrm{y}$, por supuesto, los grados de formalidad que cada momento exige en función de los rasgos situacionales (Albelda y Fernández, 2006: 6).

En la audición de la conversación real, con frecuencia, se pueden encontrar los fenómenos de habla con que se enfrentan nuestros estudiantes en sus intercambios comunicativos reales: solapamientos de habla, variedades en la curva de entonación, entonaciones expresivas, alargamientos fonéticos, contextualización de las interjecciones, identificación de ironías, elementos paralingüísticos (risas, gritos), interrupciones, desambiguación de malentendidos, equivocaciones y reinicios, etc. (Albelda y Fernández, 2006: 7).

Trabajar con una conversación es trabajar en un contexto. La conversación se realiza en un marco físico y temporal particular en el que se reconocen las características de los interlocutores (edad, sexo, profesión,...), los factores que rodean la situación comunicativa y las intenciones de los actos de habla emitidos.

A la hora de trabajar la pragmática en clase de ELE mediante programas televisivos, es conveniente especificar cada uno de los rasgos situacionales que caracterizan las secuencias comunicativas presentadas. Los registros, según Briz y Grupo Val.Es.Co. (2002), se definen por dos tipos de rasgos: situacionales y primarios, detallados a continuación:

\section{Rasgos situacionales:}

- tipo de relación social y funcional entre los interlocutores: igualdad/ desigualdad;

- relación vivencial: de proximidad o de distancia;

- marco de interacción en que se desarrolla la comunicación: ajeno, familiar; cotidiano/ no cotidiano;

- tipo de temática: especializada/ no especializada; cotidiana/ no cotidiana.

\section{Rasgos primarios:}

- finalidad de la interacción: transaccional o interpersonal; 
- presencia o ausencia de una planificación del discurso;

- tono formal o informal.

El registro formal presentará principalmente los siguientes rasgos: relación social y/o funcional de desigualdad entre los interlocutores, relación vivencial de distancia, marco de interacción no familiar o no cotidiano, temática especializada, finalidad transaccional, planificación discursiva y tono formal. El registro informal se caracterizará normalmente por los rasgos contrarios: relación social y/o funcional de igualdad entre los interlocutores, relación vivencial de proximidad, marco de interacción familiar o cotidiano, temática no especializada y/o cotidiana, finalidad interpersonal, ausencia de planificación y tono informal (Albelda y Fernández, 2006: 5).

Se ha hablado de que los rasgos anteriores caracterizan prototípicamente un registro u otro. Sin embargo, puede ocurrir que algunos de los rasgos anteriores no estén presentes y la situación siga reconociéndose como formal o informal.

Albelda y Fernández (2006: 16) recomiendan que las entrevistas se trabajen en niveles de lengua A2 (según el Marco Común Europeo de Referencia para las Lenguas), y que, a partir del nivel B1, se introduzcan las conversaciones coloquiales. Según el nivel de lengua de los estudiantes, puede que sea necesario que el profesor explique algunas palabras nuevas para los alumnos: por su concreta procedencia geográfica, por su valor excesivamente coloquial o técnico... Conviene hacerlo, especialmente, si se trata de términos o estructuras que aparecen con frecuencia en el texto oral presentado.

En cuanto al modo de trabajar las diversas posibilidades didácticas que ofrece la conversación, Albelda y Fernández (2006: 18) aconsejan actuar de lo general a lo particular. Es decir, el objetivo es que los alumnos primero alcancen una idea general del contenido de la conversación y después vayan comprendiendo y asimilando los diferentes términos y estructuras.

Una vez presentado el ejemplo de la modalidad discursiva que se trabajará a través del visionado de uno o varios programas televisivos, las tareas que mejor propician el dominio de la competencia pragmática dentro del aula son normalmente aquellas que se llevan a cabo en grupos pequeños que requieren un intercambio de información y cuyos participantes tienen un objetivo común (Sánchez Sarmiento, 2005: 592):

- actividades de interacción oral centradas en la negociación del significado;

- actividades de interacción oral centradas en el vacío de información;

- actividades sobre el uso de determinadas estrategias de comunicación;

- actividades que incluyan cierto nivel de reflexión sobre las normas y convenciones sociales en diferentes situaciones de comunicación;

- actividades que lleven al conocimiento de las normas sociales que rigen los usos lingüísticos;

- actividades con simulaciones y juegos de roles que supongan variaciones de registros de los interlocutores; 
- actividades basadas en la presentación de muestras de la lengua oral y escrita que incluyan variación de registros.

- En todas ellas el componente pragmático de la lengua está presente a través de:

- las implicaturas;

- el lenguaje coloquial;

- las estrategias de cortesía;

- la pragmática intercultural.

Cuanto más variado y más diverso sea el input, más fácil será alcanzar los objetivos (Sánchez Sarmiento, 2005: 592). Los programas televisivos deben presentar variaciones de registro, de acentos regionales, de género..., para potenciar la capacidad sociolingüística del alumno. De cara a la competencia socio-pragmática esto supone la presencia de actividades basadas en esa amplia variedad de muestras orales en las que el alumno se verá obligado a reflexionar sobre lo que se dice, el cómo se dice y sobre cuál es la intención comunicativa de los hablantes.

\section{CONCLUSIÓN}

En este artículo hemos intentado explicar algunos de los motivos por los que el programa televisivo puede resultar útil como recurso para trabajar las competencias pragmática y sociocultural en la clase de español para extranjeros, aunque consideramos que también es un recurso válido para trabajar otras competencias. Hemos destacado su carácter de documento real y auténtico, argumentando su capacidad para ofrecer información sobre el entorno sociocultural. Asimismo, hemos señalado algunas de las ventajas que presenta frente al relato fílmico, tales como el lenguaje natural y espontáneo (reflejado gracias al directo), su carácter motivador y su corta duración.

Nos gustaría que este artículo sirviera para provocar una reflexión en todos aquellos profesores interesados en el uso del material audiovisual en el aula de español, y que su aplicación en el aula influyera positivamente en el aprendizaje de todos aquellos alumnos interesados en nuestra lengua y cultura.

Las competencias pragmática y sociocultural contribuyen a mejorar la eficacia y la adecuación de la comunicación humana. El profesor de español como lengua extranjera debería considerarlas siempre a la hora de programar su trabajo para formar hablantes competentes en la lengua meta.

Aún queda mucho trabajo por hacer en este terreno y son muchos los marcos teóricos desde los que se puede abordar, pero esperamos que esto cambie en los próximos años y podamos contar con propuestas que nos ayuden a presentar este tipo de contenidos en clase. 


\section{BIBLIOGRAFÍA}

Albelda,M.y Fernández,M.J.(2006):“La enseñanza delos registros en ELE. Unaaplicación al español coloquial", Marcoele, 3. Disponible en: http://www.marcoele.com/ num/3/0218f5989b0f06708/coloquial.pdf [Consultado el 06/08/2014].

Escandell, M. V. (2004): “Aportaciones de la pragmática”, en Sánchez, J. y Santos, I. (coords.) (2004) Vademécum para la formación de profesores. Enseñar español como segunda lengua (L2)/ lengua extranjera (LE). Madrid, SGEL, pp. 179-198. Disponible en: dialnet.unirioja.es/descarga/articulo/3341984.pdf [Consultado el 07/08/2014].

Ferrer Plaza, C. (2009): "Reflexiones sobre el uso de documentos auténticos en la clase de E/LE”, en S. Rojo et alii (eds.) (2009) Anais do V Congresso Brasileiro de Hispanistas e I Congresso Internacional da Associaçâo Brasileira de Hispanistas, Belo Horizonte, Faculdade de Letras da Universidade Federal de Minas Gerais: 2363-2368. Disponible en: http://www.letras.ufmg.br/espanhol/ Anais/anais_paginas_\%202010-2501/Reflexiones\%20sobre.pdf [Consultado el 10/08/2014].

Ferrés Prats, J. (1994): Televisión y educación, Barcelona, Paidós.

Grupo Val.Es.Co. (2002): Corpus de conversaciones coloquiales, Madrid, Arco Libros.

Gutiérrez Ordóñez, S. (2004): “La subcompetencia pragmática”, en J. Sánchez e I. Santos (coords.) (2004)Vademécum para la formación de profesores de profesores. Enseñar español como segunda lengua (L2)/ lengua extranjera (LE), Madrid, SGEL: 533-552. Disponible en: http://cvc.cervantes.es/ensenanza/biblioteca_ele/ asele/pdf/16/16_00_3.pdf [Consultado el 08/08/2014].

MCER (2002): Marco Común Europeo de Referencia para las Lenguas: aprendizaje, enseñanza y evaluación. Madrid, Anaya.

Lonergan, Jack (1985): El vídeo en la enseñanza de idiomas, León, Editorial Academia.

Miquel, L y Sans, N. (1992): “El componente cultural: un ingrediente más de la clase de lengua", Madrid, Cable, 9: 15-21. Disponible en: http:/ / www.mecd.gob.es/ dctm/redele/Material RedEle/Revista/2004_00/2004_redELE_0_22Miquel. pdf?documentId=0 01e72b80e0c8d9 [Consultado el 08/08/2014].

Ruiz Fajardo, G. (1994): “Vídeo en clase: virtudes y vicios”, en L. Miquel y N. Sans (eds.) (1994) Didáctica del español como lengua extranjera: actas de Expolingua desde 1990 a 1993. (Cuadernos de tiempo libre Expolingua. E/LE 2), Madrid, Fundación Actilibre: 141-164. Disponible en: http:/ / marcoele.com/descargas/expolingua1994_ruiz. fajardo.pdf [Consultado el 15/08/2014].

Sánchez Sarmiento, R. (2005): “El reflejo de la competencia sociopragmática en materiales de ELE” en A. Álvarez et alii (eds.) (2005) La Competencia Pragmática y la Enseñanza del Español como Lengua Extranjera. Actas del XVI Congreso Internacio- 
nal de ASELE, Oviedo, Ediciones de la Universidad de Oviedo: 585-593. Disponible en: cvc.cervantes.es/ensenanza/biblioteca_ele/asele/pdf/16/16_0584. pdf [Consultado el 08/08/2014]

Soler, L. (1988): La televisión. Una metodología para su aprendizaje, Barcelona, Gustavo Gili. Soriano Fernández, S. (2009): “Cortos y sin cortes. Una propuesta didáctica para el uso del cortometraje en la clase de ELE.", Revista MarcoELE, 10. Disponible en: http://marcoele.com/descargas/10/cortos_ele_s.soriano.pdf [Consultado el 10/08/2014]. 